\title{
Cracking Phenomenon in Spot Welded Joints of Austenitic Stainless Steel
}

\author{
Ahmed M. Al-Mukhtar ${ }^{1,2}$, Qasim M. Doos ${ }^{3}$ \\ ${ }^{1}$ Faculty of Geosciences and Geoengineering, Technische Universität Bergakademie Freiberg, Freiberg, Germany; ${ }^{2}$ Al-Khawirizmie \\ College of Engineering, Baghdad University, Baghdad, Iraq; ${ }^{3}$ Mechanical Engineering Department, College of Engineering, Baghdad \\ University, Baghdad, Iraq. \\ Email: almukhtar@uni.de
}

Received August $5^{\text {th }}, 2013$; revised September 21 $1^{\text {st }}, 2013$; accepted October $9^{\text {th }}, 2013$

Copyright (C) 2013 Ahmed M. Al-Mukhtar, Qasim M. Doos. This is an open access article distributed under the Creative Commons Attribution License, which permits unrestricted use, distribution, and reproduction in any medium, provided the original work is properly cited.

\begin{abstract}
The spot welds nugget cracking of austenitic stainless steel at temperatures between $700^{\circ} \mathrm{C}-1010^{\circ} \mathrm{C}$ was investigated. Traditionally, the cracks have been observed around the spot nugget in welded temperature. Actually, these cracks are developed due to incomplete melting and inappropriate electrode pressure, which causes an expulsion of molten metal. These cracks start to grow and cause either the interface or plug fracture according to the loading type. In this work, the micro-cracks in the weld nugget were indicated for this type of steel at elevated temperature. Cracks appear in a certain range of temperature; about $700^{\circ} \mathrm{C}-750^{\circ} \mathrm{C}$. The cracks like defect and cavitations were presented. According to the fracture mechanics point of view, these cracks reduce the mechanical strength. Therefore, these cracks have to be taken into account with a certain precaution. Moreover, considering the working temperature and reducing the element may develop ferrite particles.
\end{abstract}

Keywords: Austenitic Stainless Steel; Cracking; Ferrite Contents; Fatigue Cracks; Spot Welded Joints; Weld Nugget; Weld Notches

\section{Introduction}

Welding cracks of the welded joints are considered as a serious defect. They start to grow from a certain defect until final failure. The failure tends to occur due to the crack orientation around the heat affected zone (HAZ) [1-3]. A typical through-thickness stress distribution and the fatigue critical location have been studied also at the edge of a spot weld nugget. Traditionally, the maximum stress occurs also at the interface between the two sheets [4].

Only a few studies deal with the cracking of the nugget area, and the ferrite contents of the austenitic stainless steel. In contrast, most studies deal with the aluminum welding, hot cracking, the welding process type, and the alloy compositions that determine the cracking susceptibility. Most literature showed that the cracks are initiated from the HAZ in aluminum alloy, i.e. from the periphery of spot weld nugget. The cracks were formed at elevated temperatures in the presence of liquid metal due to the metallurgical factors [5].

In addition, Lippold et al. [6] observed the crack initiation and propagation in the weld fusion zone and the
HAZ of 5083-aluminium alloy. It was found that the cracking susceptibility depended on the Magnesium contents. Therefore, Toyota reported the solidification failure in the nugget or liquation cracking in the HAZ for one of the 5000 series of aluminum alloys containing above $5 \%$ weight of $\mathrm{Mg}$ [5]. The preheating will decrease the thermal stresses and the temperature gradient. Hence, the cracking ability will be decreased.

Mirsalehi et al. [7] proposed a crack propagation-based fatigue life approach for resistance spot welds. Moreover, the effect of welding residual stresses was taken into account. The effects of spot weld diameter as well as the location of crack initiation have been predicted. Lin et al. [8] examined the fatigue crack paths near the spot welds in the square-cup, lap-shear and coach-peel specimens. The stress intensity factor (SIF) solutions have been used to predict the fatigue lives. SIF and fatigue lives for welding joint can be calculated using Fracture Analysis Code-2 dimension (Franc2D) for different types of materials, cracks and weld geometries $[9,10]$.

However, there is an increasing use of stainless steel 
alloys in the industry due to their corrosion resistance; still there is a lack of practical information on their cracking due to the spot welding process. The fatigue crack appears to be initiated near the weld notch tip. Then, it will be propagated through the sheet thickness with a crack kink path angle (see Figure 1). The crack paths have different propagation possibilities according to the maximum stress direction.

In this work, the effects of heating on the microstructural characteristics and the cracking ability were presented. High temperature cracks have been observed in the center of the weld nugget in which a specific microstructure was developed with a certain ferrite content. Microhardness profiles and the weld nugget defects have been presented.

\section{Materials and Experiments}

\subsection{Materials}

Austenitic stainless steel, AISI (321), cold rolled $1.5 \mathrm{~mm}$ thickness without coating has been used. The overlapped specimens were welded. The chemical composition and the mechanical properties are given in Tables $\mathbf{1}$ and $\mathbf{2}$, respectively. The electrodes are RWMA class-1, pure copper materials which have a high thermal and electrical conductivity have been used [11].

\subsection{Microhardness and Microstructure Investigation}

The weld cracking and fracture toughness may be influenced by the weld hardness distribution. Therefore, the microhardness was investigated along the faying surface (longitudinal), and through the thickness (traverse), respectively, see Figure 2. The Vickers mirohardenss is employed across the weld nugget, HAZ and the base materials using the conventional microhardness tester

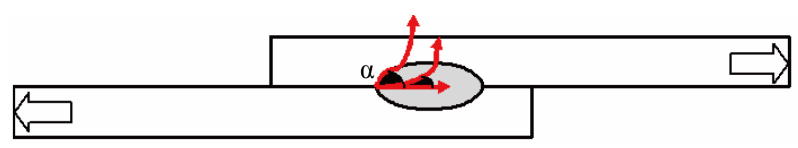

Figure 1. The typical fatigue crack paths with a kink angle $\alpha$.

Table 1. Chemical composition of stainless steel sheets.

\begin{tabular}{cccccccccccc}
\hline $\begin{array}{c}\text { Steel } \\
\text { designation }\end{array}$ & $\mathrm{C}$ & $\mathrm{Cr}$ & $\mathrm{Ni}$ & $\mathrm{Mn}$ & $\mathrm{V}$ & $\mathrm{Mo}$ & $\mathrm{Si}$ & $\mathrm{Ti}$ & $\mathrm{Nb}$ & $\mathrm{Cu}$ & $\mathrm{Fe}$ \\
\hline AISI 321 & 0.05 & 19 & 8.8 & 1 & 0.06 & 0.5 & 0.72 & 0.46 & 0.01 & 0.31 & Rem \\
\hline
\end{tabular}

Table 2. Mechanical properties of stainless steel sheets.

\begin{tabular}{cccc}
\hline $\begin{array}{c}\text { Tensile } \\
\text { strength }\end{array}$ & $\begin{array}{c}\text { Yield strength } \\
(0.2 \% \text { offset })\end{array}$ & Elongation & Reduction of area \\
\hline $600 \mathrm{MPa}$ & $205 \mathrm{MPa}$ & $40 \%$ & $50 \%$ \\
\hline
\end{tabular}

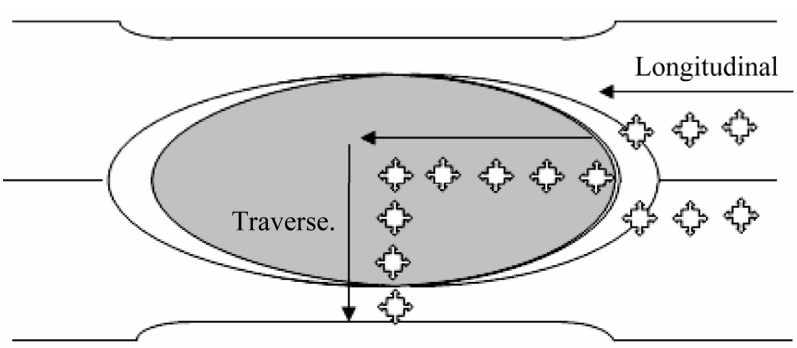

Figure 2. The microhardness measurements.

(JTT Digital micrometer taster, type JMT7 type A, Toshi INC.) with 300 gr loads. The average of the two readings at least was calculated. As-welded, and heat treated specimens were welded at $7.2 \mathrm{kA}$, and 60 cycles.

The percentage of ferrite content was indicated using the ferrite scope M11 instrument (Fisher manufacturing). The sensing probe passed over the test specimen. The calibration process was carried out in advance.

The steels were annealed after welding to obtain maximum softness and ductility. Unlike the unstablized grades, these steels did not require water quenching or other acceleration of cooling from the annealing temperature to prevent subsequent intergranular corrosion [12, 13]. Therefore, air-cooling is generally adequate. Annealing was performed at $1010^{\circ} \mathrm{C}$. In light section might be held at this temperature for 3 minutes per $2.5 \mathrm{~mm}$. The time passed for thickness $(1.5 \mathrm{~mm})$ will be 2 minutes approximately. Stress relieving at temperature $750^{\circ} \mathrm{C}$ for $2 \mathrm{~min}$ is advisable when the service environment is known to be suspected to cause stress corrosion. By using the stabilized or extra low-carbon grades, heating at stress relieve temperature could avoid the intergranular precipitates of chromium [14].

\section{Results and Discussion}

\subsection{Microhardness Distributions}

The microhardness for as-welded, annealed, and stress relieved specimens has been measured equal to 275, 210 and $240 \mathrm{HV}$, respectively. The higher hardness distribution in longitudinal direction was found in HAZ and dropped beyond the HAZ, see Figure 3 . The hardness increases again at the center of the nugget. Since the initial contact at HAZ through a contact bridge (asperities), the asperities will be flattened (enlarged) due to the heating concentration. Therefore, the heat input increases the softening of the weld and reducing the stresses. The traverse microhardness profile has a higher value in the center of the weld nugget. Again, the microhardness drops through thickness beyond the center. The transverse hardness increases again at HAZ. This is because the compressive stresses will be developed through the thickness due to the nugget growing in a relatively cold 

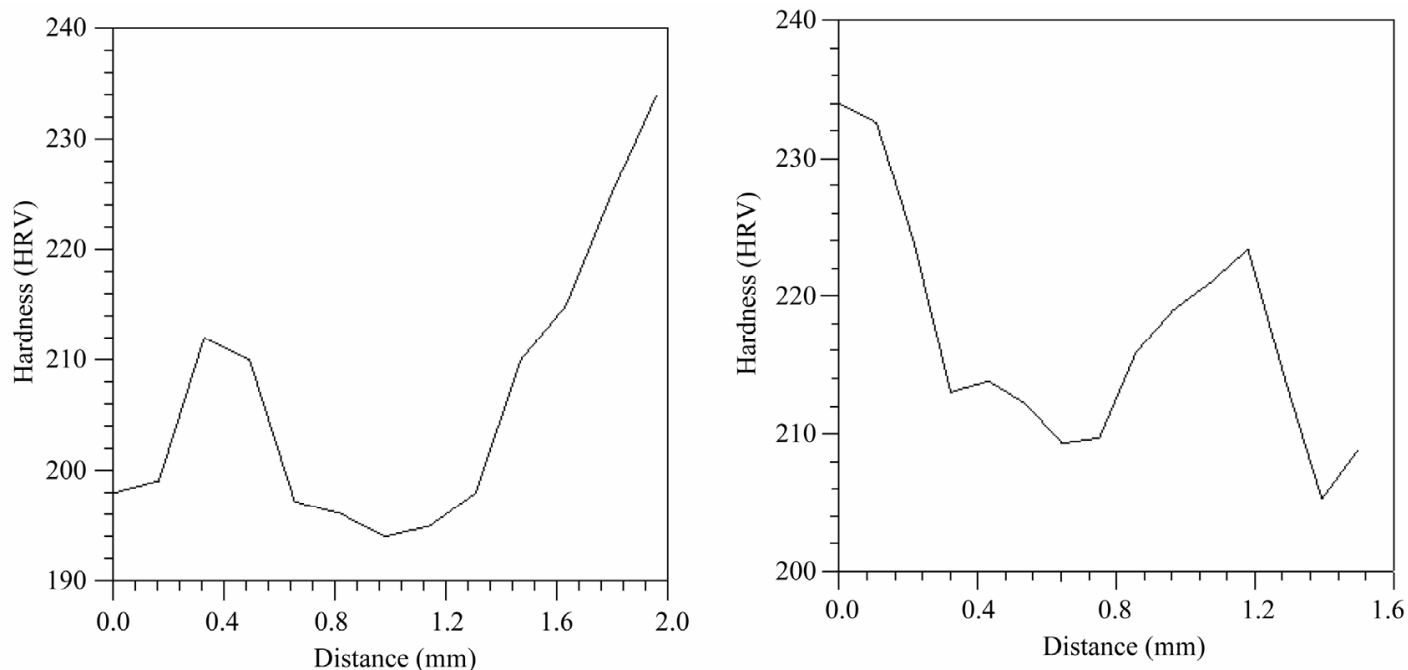

(a)
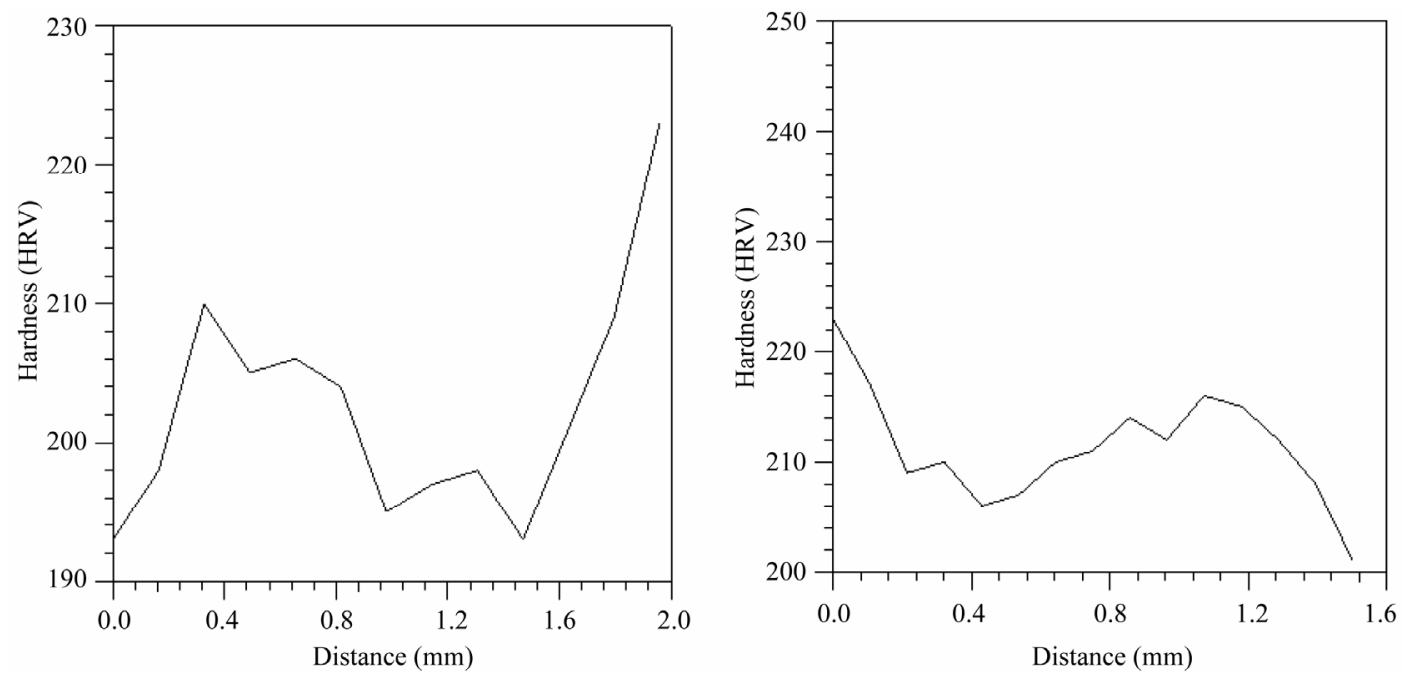

(b)
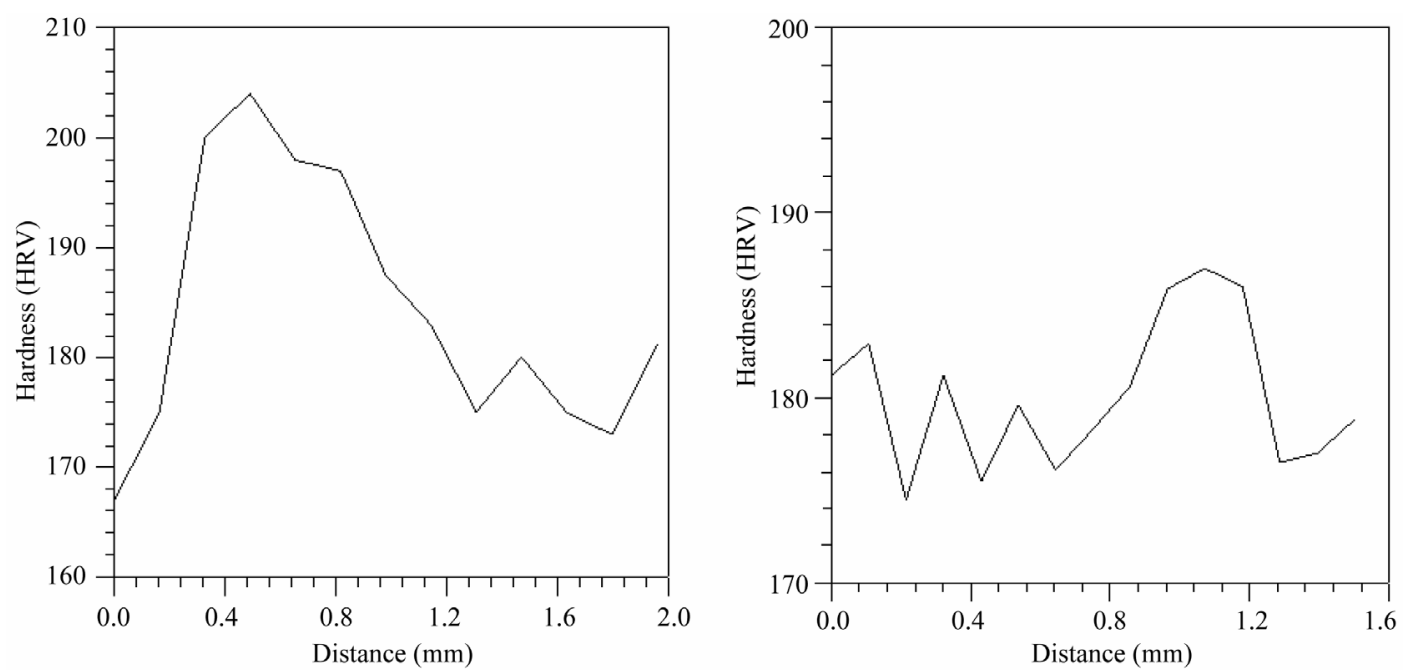

(c)

Figure 3. Microhardness profiles at different conditions. (a) As-welded conditions: (left) Longitudinal, (right) Transverse; (b) Stress relieved conditions: (left) Longitudinal, (right) Transverse; (c) Annealed conditions: (left) Longitudinal, (right) Transverse. 
sheet metal. The forge pressure of the electrodes balances the nugget growing force. Therefore, the compressive stresses are created around the nugget. It was found that the microstructural cracking is related with the hardness and heat input. However, the welding process sequence may also produce cracks.

\subsection{High Temperature Crack Growth and Ferrite Contents}

The etching solution of $10 \mathrm{ml}$ acetic acid, $15 \mathrm{ml}$ hydrochloric acid (HCL), $10 \mathrm{ml}$ nitric acid $\left(\mathrm{HNO}_{3}\right)$, and two drops of glycerol was used for the spot weld area according to the American Welding Society (AWS) [12]. The cracks have been appearing around the periphery of the spot nugget due to the stress concentration and the notch effect in HAZ. The multi-site cracking around the weld nugget and the expelled fused metal are shown in Figures 4(a) and (b), respectively. Fracture mechanics with help of FE have been used to estimate the crack length and path in other welded joints $[10,15]$.

The molten weld metal will be poured during the process, see Figure 5(a). Figure 5(b) shows the irregular shape cavity which produced after the solidification. The irregular shape cavity will initiate the crack that propagates through the weld metal. The crack will be extended during the loading, or during the electrodes removing that were sticking to the surfaces as illustrated in Figure 1. This crack is also related to the electrode pre- ssure, cooling rate, and the fused metal depth between the two sheets. Weld metal that solidifies as ferrite inherently much less susceptible to cracking than that which solidifies as austenite [16]. The mixed structures which solidify with ferrite contents more than 3\% at room temperature have in practice adequate resistance to hot cracking. However, the austenite weld metal with smaller amount of ferrite is very crack sensitive. The crack growth occurred in the weldments of austenitic stainless steel at the temperature of stress relieving treatment of $750^{\circ} \mathrm{C}$ with $1 \%$ ferrite content, see Figure 6 . Table 3 shows the ferrite percentage in different conditions.

Kamaraj et al. [17] studied the crack growth of unwelded stainless steel. They have found that the crack growth takes place at $600^{\circ} \mathrm{C}$ along the interface between the austenite and the arm of delta ferrite in the weldments of stainless steel type 308. In this work, the stress relieving temperature is exceeded $500^{\circ} \mathrm{C}$ and will develop about $1 \%$ of ferrite at a temperature of $750^{\circ} \mathrm{C}$, see Table 3. The specimens were finally annealed at $1010^{\circ} \mathrm{C}$ which produce the reliable microstructure with a minimum number of defects and about $0.24 \%$ of ferrite, see Figure 7.

\subsection{Spot Welding Defects}

Numbers of individual defects appear in the spot weld nugget. The allowable defect dimensions and the initial

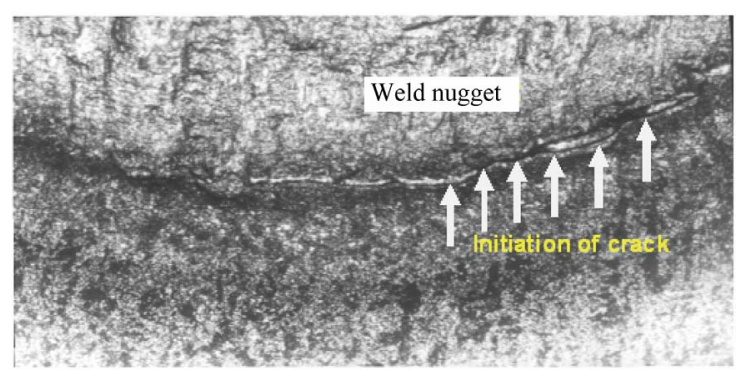

(a)

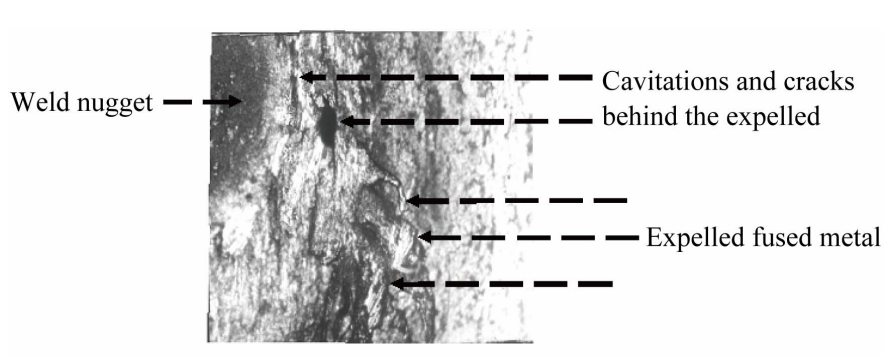

(b)

Figure 4. Fracture beside the weld bead; (a) crack initiation around the weld nugget; (b) the expelled weld metal.

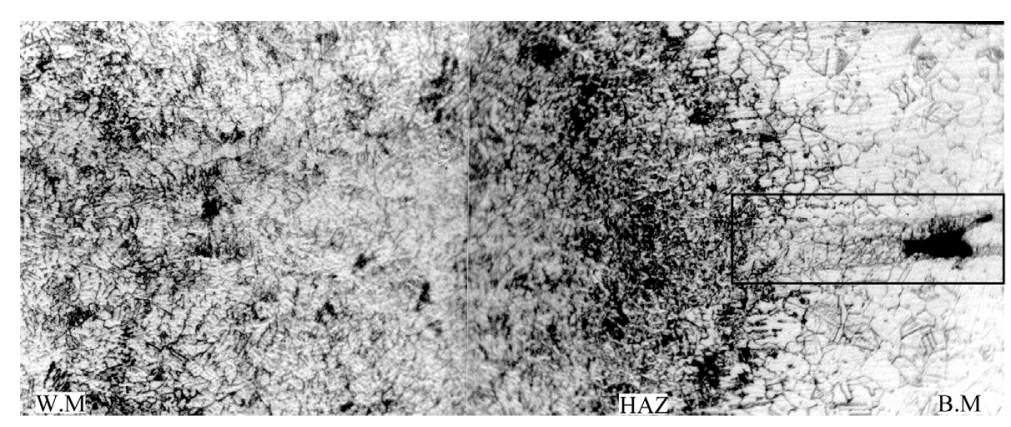

(a)

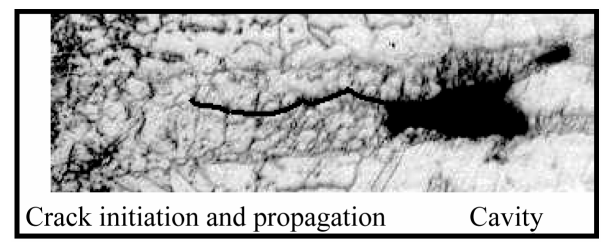

(b)

Figure 5. As-welded structures, $I=7.2 \mathrm{kA}, \mathrm{T}=60$ cycles; (a) and (b) cracking and the cavity in the solidified metal around HAZ. 

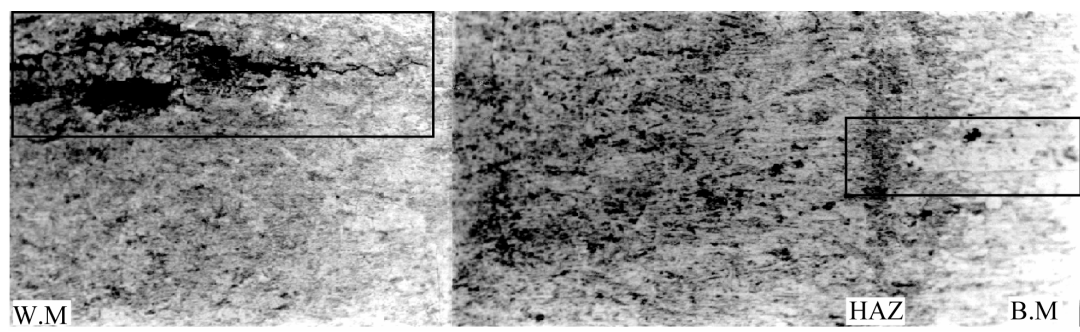

(a)

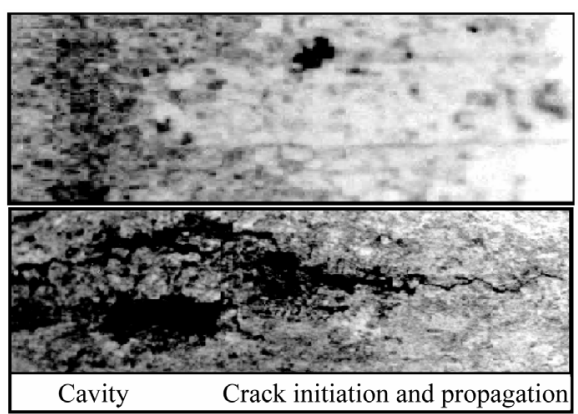

(b)

Figure 6. Stress-relieved structures, $I=7.2 \mathrm{kA}, \mathrm{T}=60$ cycles; (a) cracking of the weld nugget area; (b) the interface molten metal.

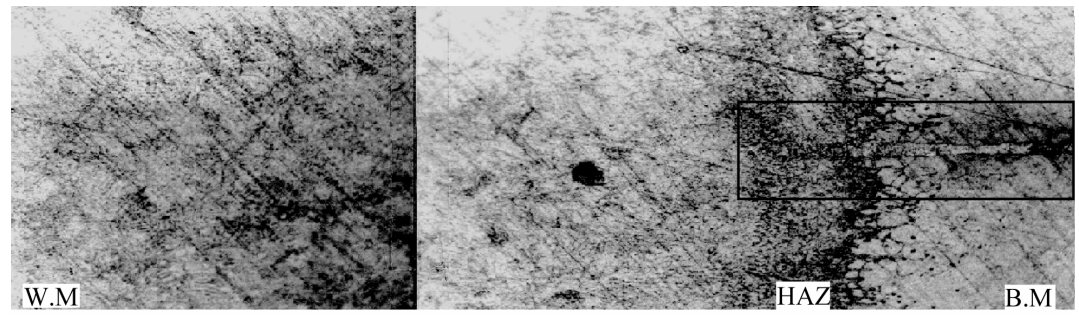

(a)

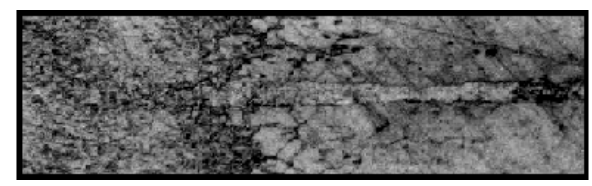

(b)

Figure 7. Annealed structures, $I=7.2 \mathrm{kA}, \mathrm{T}=60 \mathrm{cycle}$; (a) and (b) weld area and the interface molten metal.

Table 3. Delta-ferrite contents.

\begin{tabular}{ccccccccc}
\hline Spec. No. & I (kA) & T (cycle) & \multicolumn{5}{c}{ Delta-ferrite Amount from the center of the spot weld (\%) } \\
\hline 1 (As-welded) & 7.2 & 60 & 1.4 & 1.2 & 1 & 0.8 & 0.24 & 0.2 \\
2 (As-welded) & 5.8 & 45 & 0.9 & 0.76 & 0.67 & 0.23 & 0.22 & 0.2 \\
3 (As-welded) & 3.7 & 30 & 0.43 & 0.27 & 0.25 & 0.24 & 0.2 & 0.2 \\
4 (annealed) & 7.2 & 60 & 0.24 & 0.22 & 0.21 & 0.2 & 0.2 & 0.2 \\
5 (stress relieved) & 7.2 & 60 & 1 & 0.9 & 0.8 & 0.65 & 0.2 & 0.2 \\
\hline
\end{tabular}

crack length have been determined using Franc2D [10]. The large cavity is the most conventional defects that reduce the joint quality and fatigue strength. Figure 8(a) shows the expulsion cavity and the surrounding small shrinkage cavity that occurs at $7.2 \mathrm{kA}$, and 60 cycle for $1.5 \mathrm{~mm}$ thickness of stainless steel. Practically, most welds have a shrinkage cavity in the center of the weld nugget [18]. The finite element simulation could be used to determine the regions of stress concentration which in turn determine the crack initiating and fracture strength [19]. A cavity which occurs from the heavy expulsion of molten metal may extend over a part of the fused area in a few millimeters according to the welding parameters and metal velocity. The metal shrinkage porosity and cavity will extend and accelerate the crack propagation under the load. The high welding setting (i.e., high welding current and time) causes a high speed movement of the weld metal in the form of the vortex. Therefore, an opposite force against the electrodes forge direction will be developed. Hence, an expelled metal will be extruded once the nugget force increases more than the supporting force. The electrode force should be sufficient to balance the compressive stresses that developed within the nugget. Moreover, welding settings have to be compatible with the sheet thickness. It is to be emphasized that only the highly plastic metal in the hot zone at the center of the spot nugget will be expelled out. Splashing in spot welding reduces the cross section being welded. Figure 8(b) shows the fractured specimens and the expelled molten metal from the hot zone.

\section{Conclusion}

In spot welding, the HAZ and weld nugget areas have a critical role. The cracking phenomena have been investigated in spot-welded joint. The cracking ability is a major problem in welded structures. This is because the cracks reduce the joint strength. The cracking behavior at high temperature was observed. It is concluded that the cracks are initiated from the center of sport weld nugget 


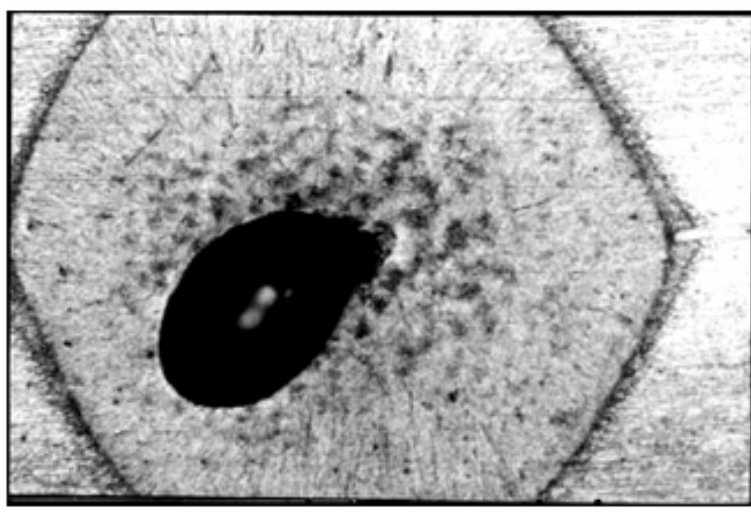

(a)

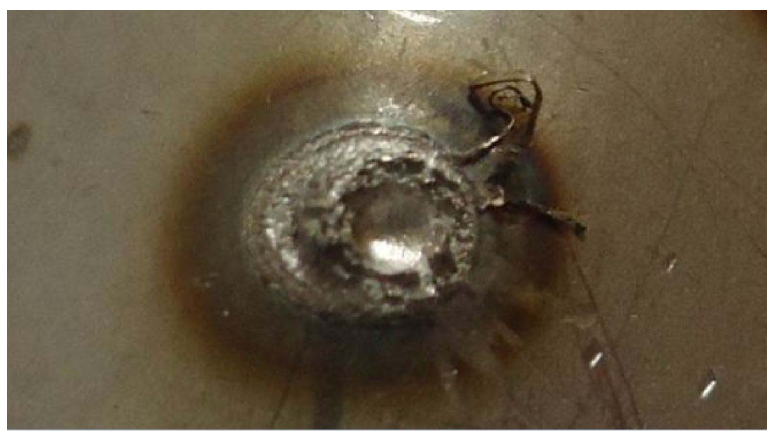

(b)

Figure 8. (a) Large cavity due to the metal expulsion (Etching: $10 \mathrm{ml}$ acetic acid, $15 \mathrm{ml}$ hydrochloric acid, $10 \mathrm{ml}$ nitric acid and 2 drops of glycerol); (b) The expelled of plastic metal from the hot zone.

at the temperature up to $750^{\circ} \mathrm{C}$ where the amount of produced ferrite is about $1 \%$. The crack growth will take place also along the interface between the austenite and delta ferrite. A certain precaution must be taken by considering the temperature limits and by reducing the element that may develop ferrite particles. However, the crack may also be developed at the welding conditions from HAZ adjacent to the weld nugget due to notch stress concentration. If the electrode pressure is not sufficient to balance the developed force within the spot due to the nugget growth, part of the weld metal will be expelled out. The expulsion of the highly plastic metal from the hot zone at the center of the spot will increase the stresses near the point where the loss of metal occurs. Actually, the cracks around the weld nugget can be developed also due to the electrodes sticking to the surface. By removing the electrodes at the time when the weld nugget is still ductile, the crack will be initiated and grow toward the nugget center.

\section{Acknowledgements}

The first author would like to thankfully appreciate the support received from the Technische Universität Bergakademie Freiberg, Faculty of Geosciences and Geoengi- neering, Department for Geology, Germany. The support from Institute of International Education (IIE), USA, is gratefully appreciated.

\section{REFERENCES}

[1] M. Vural and A. Akkus, "On the Resistance Spot Weldability of Galvanized Interstitial Free Steel Sheets with Austenitic Stainless Steel Sheets,” Journal of Materials Processing Technology, Vol. 153-154, 2004, pp. 1-6.

[2] G. Mukhopadhyay, S. Bhattacharya and K. K. Ray, "Strength Assessment of Spot-Welded Sheets of Interstitial Free Steels," Journal of Materials Processing Technology, Vol. 209, No. 4, 2009, pp. 1995-2007.

[3] H. Yu, S. Yang, H. Y. Kang, H. G. Kim and K. S. Kim. "Fatigue Life Analysis of Spot Weldment of Cold Rolled and High Strength Steel Using FEM," Transaction of the Korean Society of Machine Tool Engineers, Vol. 17, No. 5, 2008, pp. 58-63.

[4] M. M. Rahman, "Fatigue Life Prediction of Spot-Welded Structures: A Finite Element Analysis Approach,” European Journal of Scientific Research, Vol. 22, No. 3, 2008, pp. 444-456.

[5] J. Senkara and H. Zhang, "Cracking in Spot Welding Aluminum Alloy AA5754,” Welding Journal-New York, Vol. 79, No. 7, 2000, pp. 194s-201s.

[6] J. C. Lippold, E. F. Nippes and W. F. Savage, “An Investigation of Hot Cracking in 5083-0 Aluminum Alloy Weldments," Welding Journal, Vol. 56, No. 6, 1977, pp. 171s-178s.

[7] S. E. Mirsalehi and A. H. Kokabi, "Fatigue Life Estimation of Spot Welds Using a Crack Propagation-Based Method with Consideration of Residual Stresses Effect," Materials Science and Engineering: A, Vol. 527, No. 23, 2010, pp. 6359-6363.

http://dx.doi.org/10.1016/j.msea.2010.06.070

[8] S. Lin, J. Pan, P. Wung and J. Chiang, “A Fatigue Crack Growth Model for Spot Welds under Cyclic Loading Conditions," International Journal of Fatigue, Vol. 28, No. 7, 2006, pp. 792-803. http://dx.doi.org/10.1016/j.ijfatigue.2005.08.003

[9] A. M. Al-Mukhtar, H. Biermann, P. Huebner and S. Henkel, "Comparison of the Stress Intensity Factor of LoadCarrying Cruciform Welded Joints with Different Geometries," Journal of Materials Engineering and Performance, Vol. 19, No. 6, 2010, pp. 802-809. http://dx.doi.org/10.1007/s11665-009-9552-1

[10] A. M. Al-Mukhtar, H. Biermann, P. Huebner and S. Henkel, "Determination of Some Parameters for Fatigue Life in Welded Joints Using Fracture Mechanics Method," Journal of Materials Engineering and Performance, Vol. 19, No. 9, 2010, pp. 1225-1234. http://dx.doi.org/10.1007/s11665-010-9621-5

[11] A. M. Al-Mukhtar, "Spot Welding Efficiency and Its Effect on Structural Strength of Gas Generator and Its Performance,” M.Sc. Thesis, Baghdad University, Baghdad, 2002.

[12] "Handbook, Welding," American Welding Society, New 
York, 1978.

[13] American Society for Metals, "Metal Handbook: Welding and Brazing," 8th Edition, ASM International, Materials Park, 1971.

[14] A. I. Pugachev, N. B. Demkin and V. I. Ryazantsev, "Dimensions of Initial Contact in Spot Welding of Light Alloys,” Welding Research Abroad, April 1969, pp. 7276.

[15] A. M. Al-Mukhtar, H. Biermann, P. Huebner and S. Henkel, "The Effect of Weld Profile Geometries of Butt Weld Joints on Fatigue Life under Cyclic Tensile Loading," Journal of Materials Engineering and Performance, Vol. 20, No. 8, 2011, pp. 1385-1391. http://dx.doi.org/10.1007/s11665-010-9775-1

[16] J. F. Lancaster, “The Metallurgy of Welding, Brazing and
Soldering,” George Alden and Unwin LTD., London, 1970.

[17] M. Kamaraj and V. M. Radhakrishnan, "High Temperature Crack Growth in Austenitic Weld Metal,” Engineering Fracture Mechanics, Vol. 33, No. 5, 1989, pp. 801811.

[18] Q. Doos and A. M. Al-Mukhtar, "Static Strength Behavior of Austenitic Stainless Steel Sheet," Journal of Engineering College, Baghdad University, Vol. 10, No. 2, 2004.

[19] A. M. Al-Mukhtar, "Investigation of the Thickness Effect on the Fatigue Strength Calculation,” Journal of Failure Analysis and Prevention, Vol. 13, No. 1, 2013, pp. 63-71. http://dx.doi.org/10.1007/s11668-012-9629-2 